\title{
EVS29 Symposium \\ Montréal, Québec, Canada, June 19-22, 2016
}

\section{Projected Greenhouse Gas Emissions for Plug-in Electric Vehicles}

\author{
Marcus Alexander ${ }^{1}$, Luke Tonachel ${ }^{2}$ \\ ${ }^{1}$ Marcus Alexander (corresponding author) Electric Power Research Institute, 3420 Hillview Ave., Palo Alto, CA \\ 94304,USA,malexander@epri.com \\ ${ }^{2}$ Natural Resources Defense Council, 40 West $20^{\text {th }}$ Street, New York, NY 10011, USA
}

\begin{abstract}
Summary
Plug-in electric vehicles propelled by stored electrical energy do not directly emit greenhouse gas emissions during operation, but indirect emissions can occur when electricity is generated to recharge the vehicle batteries. Determining the mix of power plants that would supply this electricity is difficult due to the technical complexity inherent in grid modeling. This paper describes best practices for projecting future grid emissions and uses these best practices to forecast grid emissions in the United States. These projections indicate that plug-in electric vehicles can significantly reduce transportation sector emissions even when accounting for the emissions associated with vehicle electrification.
\end{abstract}

Keywords: electricity, emissions, environment, United States of America

\section{Introduction}

Plug-in electric vehicles (PEVs), including battery electric vehicles (BEVs) and plug-in hybrid electric vehicles (PHEVs), have the potential to significantly reduce transportation emissions. BEVs are propelled exclusively by energy from the electricity grid and stored in batteries, and PHEVs are propelled by a combination of grid-derived energy and power produced on-board by an internal combustion engine or fuel cell. Both types of vehicles have greatly reduced direct emissions while operating on electricity, and qualify to varying levels as 'zero emissions vehicles' in different regulatory contexts. However, recharging the batteries from the grid requires increased generation from power plants, and can result in indirect emissions if electricity is sourced from generation sources that have emissions. Due to the nature of electricity grids, it is difficult or impossible to determine the precise source of electricity for a given load, so it is necessary to use complex analysis to attribute emissions to this electricity. Further, forecasting future generation is even more difficult since sophisticated tools are required to model the grid, and there are different approaches to estimating the effects of future load, which can lead to significantly different results. This report describes a methodology for projecting the effects on the grid of introducing large numbers of PEVs and describes the results of using this methodology to project grid greenhouse gas emissions in the United States from 2015 to 2050.

This paper summarizes the discussion and greenhouse gas emissions results in a joint study of the Electric Power Research Institute and Natural Resources Defense Council, Environmental Assessment of a Full Electric Transportation Portfolio (see [1] and [2]). The full reports describe an extensive literature review, discuss methodological development in detail, provide additional information on data sources and model configuration, and document the full results. 


\section{Emissions Projection Best Practices}

Projecting grid emissions is difficult due to the highly technical nature of grid analysis and due to different approaches for estimating the effects of incremental load. For the analysis described in this report, best practices were developed for modeling the effects on the grid due to the additional charging load due to the introduction of large numbers of PEVs.

One important best practice that distinguishes this work from previous work is the use of a 'large-scale' marginal grid modeling methodology. In this methodology, incremental load is added to a full grid model over time, as the load will occur in reality (this model should at a minimum include capacity expansion and retirement and a full suite of emissions policies). Using a realistic load change and a comprehensive grid model ensures that the grid is able to respond with a combination of redispatch of existing resources and introduction of new resources. Alternately, adding load at an unrealistic rate or using an incomplete grid model will result in grid behavior that exceeds regulated limits and provides a distorted view of the potential benefits of PEVs.

\section{Transportation Submodel}

The analysis considered the electrification of a large amount of light-duty and heavy-duty vehicles and nonroad equipment. This large-scale shift towards electricity occurs over a long time period, so it was necessary to create long-term projections of the changes in the transportation sector. This section describes the development of models for each segment of the sector.

\subsection{Electrification of On-road Vehicles}

The electrification of on-road vehicles was modeled by dividing on-road vehicles into categories that could be electrified with near-term technology and those that could not, then assuming that electrifiable categories were electrified based on an aggressive, but plausible, introduction trajectory described by the U.S. National Research Council [3]. Table 1 shows which on-road vehicle categories were electrified. Most vehicle classes that did not require long distance travel with heavy loads were considered to be electrifiable.

Table 1: Electrification of vehicle categories

\begin{tabular}{|c|c|c|c|c|}
\hline \multirow{4}{*}{ 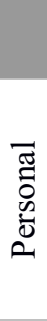 } & Vehicle Class & $\begin{array}{l}\text { PEVs } \\
\text { Allowed }\end{array}$ & $\begin{array}{l}\text { Conventional } \\
\text { Vehicles Only }\end{array}$ & Vehicle Class Description \\
\hline & Motorcycle & $\mathrm{X}$ & & Motorcycle \\
\hline & Passenger Car & $\mathrm{X}$ & & Passenger Car \\
\hline & Passenger Truck & $\mathrm{X}$ & & $\begin{array}{l}\text { Minivans, pickups, SUVs, and other } 2 \text {-axle / 4-tire } \\
\text { trucks used primarily for personal transportation } \\
\text { This category is approximately } 93 \% \text { light-duty and } \\
7 \% \text { heavy-duty (on a VMT basis). }\end{array}$ \\
\hline \multirow{7}{*}{ 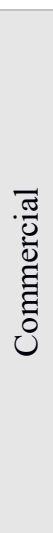 } & $\begin{array}{l}\text { Light Commercial } \\
\text { Truck }\end{array}$ & $\mathrm{X}$ & & $\begin{array}{l}\text { Minivans, pickups, SUVs, and other } 2 \text {-axle / 4-tire } \\
\text { trucks used primarily for commercial applications } \\
\text { This category is approximately } 83 \% \text { light-duty and } \\
17 \% \text { heavy-duty (on a VMT basis). }\end{array}$ \\
\hline & Intercity Bus & & $\mathrm{X}$ & $\begin{array}{l}\text { Buses that are not transit buses or school buses (e.g., } \\
\text { those used primarily for city-to-city transport) }\end{array}$ \\
\hline & Transit Bus & $\mathrm{X}$ & & Buses used for public transit \\
\hline & School Bus & $\mathrm{X}$ & & School and church buses \\
\hline & Refuse Truck & $\mathrm{X}$ & & Garbage and recycling trucks \\
\hline & $\begin{array}{l}\text { Single-unit } \\
\text { Short-haul Truck }\end{array}$ & $\mathrm{X}$ & & $\begin{array}{l}\text { Single-unit trucks with majority of operation within } \\
200 \text { miles of home base }\end{array}$ \\
\hline & $\begin{array}{l}\text { Single-unit } \\
\text { Long-haul Truck }\end{array}$ & & $\mathrm{X}$ & $\begin{array}{l}\text { Single-unit trucks with majority of operation outside } \\
\text { of } 200 \text { miles of home base }\end{array}$ \\
\hline a & Motor Home & & $\mathrm{X}$ & Motor Home \\
\hline & $\begin{array}{l}\text { Combination } \\
\text { Short-haul Truck }\end{array}$ & & $\mathrm{X}$ & $\begin{array}{l}\text { Combination trucks with majority of operation within } \\
200 \text { miles of home base }\end{array}$ \\
\hline ¿ี & $\begin{array}{l}\text { Combination } \\
\text { Long-haul Truck }\end{array}$ & & $\mathrm{X}$ & $\begin{array}{l}\text { Combination trucks with majority of operation } \\
\text { outside of } 200 \text { miles of home base }\end{array}$ \\
\hline
\end{tabular}


For the electrified vehicle categories, it was assumed that vehicles would be replaced by a mix of plug-in hybrid electric vehicle (PHEV) and battery electric vehicles (BEV) types, which would change over time as battery technology progressed. Figure 1 shows the combined effects of the introduction trajectory referenced above and the mix of PEVs on new vehicle sales. The mix shifts from an emphasis on PHEVs in the pre2030 timeframe to an emphasis on BEVs in the post-2030 timeframe (the average BEV is also assumed to increase in range, but the mix of ranges is not broken out).

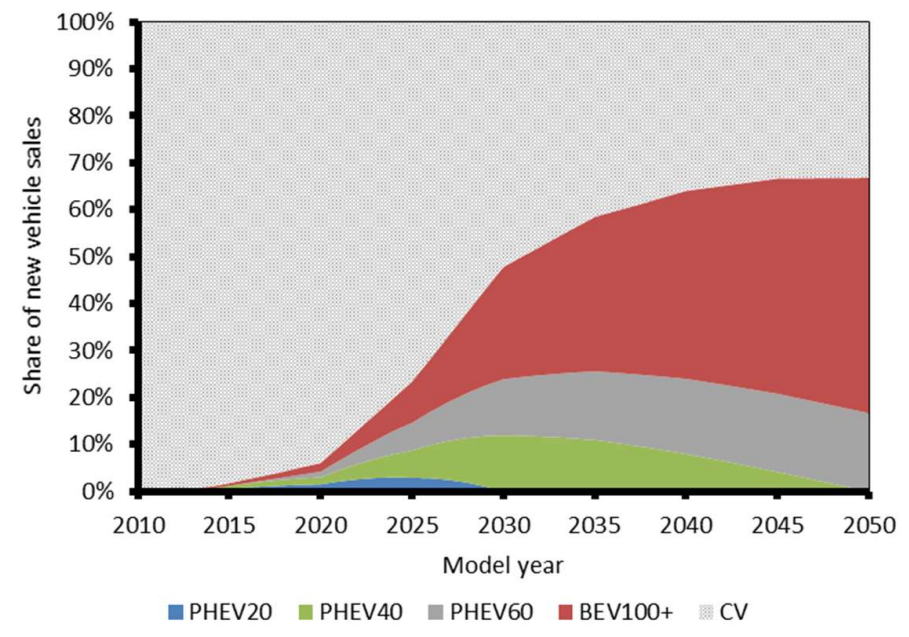

Figure 1: Distribution of new-vehicle sales among various types, for vehicle categories that include PEV sales

In the transportation model, the new PEVs sold are assumed to replace conventional vehicles which are improving over time in response to current and anticipated fuel economy standards. Each of the vehicle classes discussed in Table 1 is assumed to improve based on different trajectories. Light-duty vehicles are expected to improve particularly quickly due to the Corporate Average Fuel Economy standard and automotive greenhouse gas emissions standard; Figure 2 shows the resulting trajectory for new vehicle fuel economies (Heavy-duty vehicles were also assumed to improve, but at a slower rate which did not include recent rulemaking for the fuel economy of heavy-duty vehicles. EPRI-NRDC Volume 2 ([2]) discusses a sensitivity case where heavy-duty vehicle fuel economy improves at a faster rate and light-duty vehicle fuel economy improves at a faster rate after 2025).

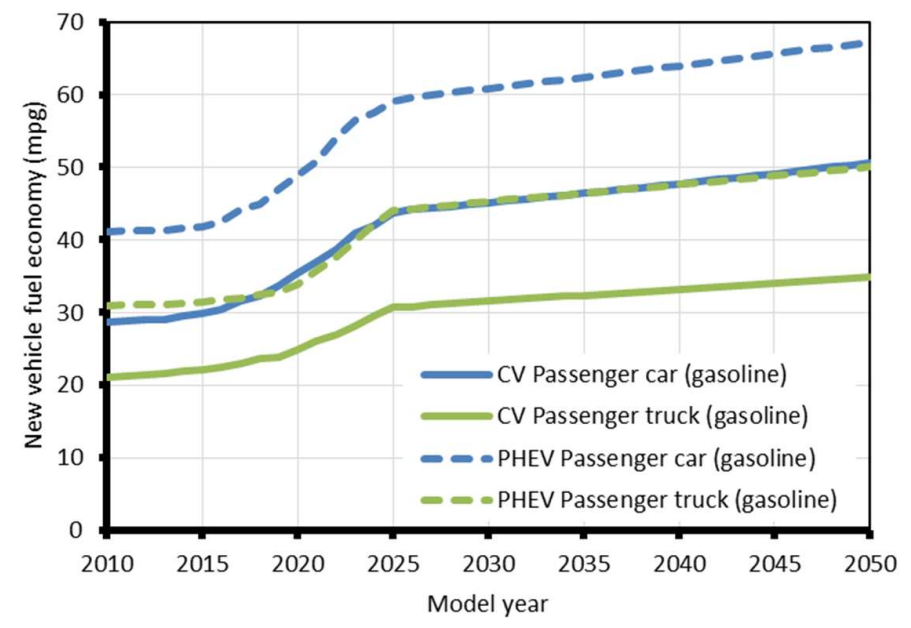

Figure 2: Fuel economy of selected light-duty vehicle categories (new vehicles)

\subsection{Electrification of Non-road Equipment}

The analysis also considered electrification of non-road equipment, although much less petroleum is used for non-road equipment than on-road vehicles to opportunities for greenhouse gas reduction are more limited 
(electrification of non-road equipment had a larger effect on air quality, as described in [4]). Figure 3 shows the fraction of 2015 non-road emissions that were considered to be electrifiable in this analysis (this inventory does not include the fuel used by trains, ships, and aircraft during long-distance travel between ports, which is also assumed to be non-electrifiable). For the electrifiable categories, each device type has a different market-acceptance trajectory, but none reach $100 \%$, so the direct emissions represented by the green patches in Figure 3 are reduced but not eliminated.

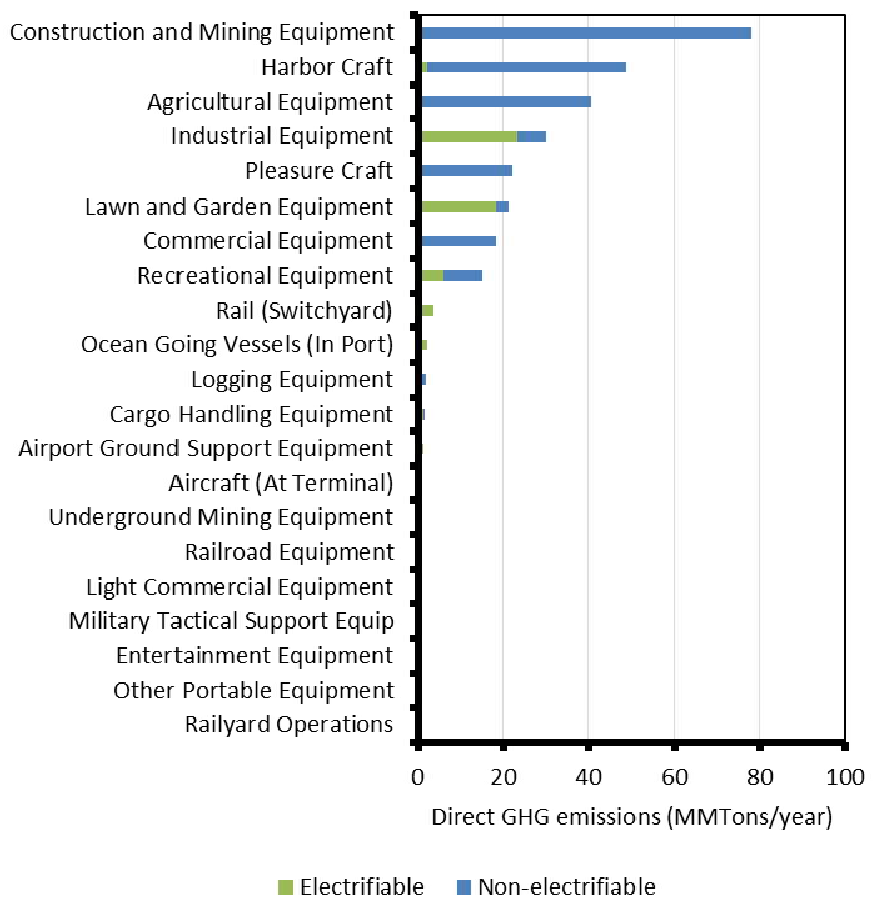

Figure 3: Direct greenhouse gas emissions from non-road equipment considered in this report for 2015

\section{Electricity Grid Modeling}

The load required to charge the PEVs and non-road devices described in Section 3 was applied to a detailed grid model to project incremental generation. The analysis used EPRI's U.S. Regional Economy, Greenhouse Gas, and Energy (US-REGEN) model for two different scenarios, the Base Greenhouse Gas (GHG) Scenario and the Lower GHG Scenario. The Base GHG Scenario incorporated a large set of assumptions about future policy, electricity fuel prices, and technology developments which represent 'expected' changes to the grid given current trends. The Lower GHG Scenario additionally assumed that an additional carbon cost was imposed on direct emissions from generators, starting in 2021 at a cost of $\$ 20 /$ metric ton of carbon dioxide and increasing in 5 -year timesteps by $28 \%$ (average annual rate of $5 \%$ per year). As discussed in Section 2, the grid modeling used a large-scale marginal approach with least-cost dispatch, a full suite of modeled criteria emissions policies, endogenous capacity expansion and retirement, and realistic rates and magnitudes of load increase. Notably, the Clean Power Plan was not modeled since it was finalized after modeling was completed, but the Environmental Protection Agency's modeled total grid greenhouse gas emissions are between the two modeled scenarios in 2030, the beginning of the full compliance period for the Plan.

\subsection{Generation without Transportation Electrification}

Figure 4 shows the changes in generation for each scenario for the non-electrification case. In both scenarios generation increases over time due to load increases in non-transportation sectors, and this additional load is met by increasing shares of renewable generation. In the Lower GHG Scenario, the increased focus on reducing GHG emissions results in a more rapid decline in coal generation and a reduction in natural gas generation. These generation reductions are compensated for by an increase in renewable generation. 

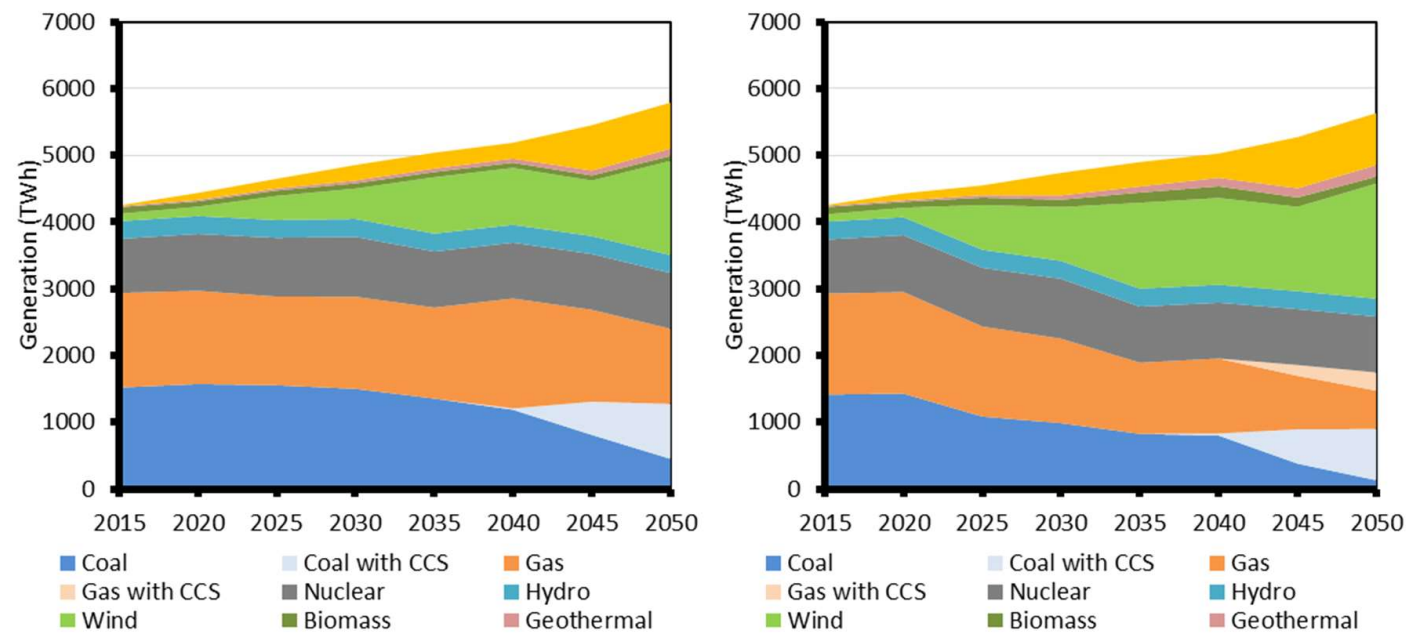

Figure 4: Energy generation in the Base GHG Scenario (left) and Lower GHG Scenario (right), without transportation electrification load

\subsection{Incremental Generation Due to Transportation Electrification}

The additional load due to transportation electrification leads to additional generation. Figure 5 shows the sources for incremental generation in both scenarios, which primarily come from combined cycle natural gas, with some additional renewable generation. In the post-2040 timeframe coal with carbon capture and storage (CCS) contributes significant amount of generation, particularly in the Lower GHG Scenario. In 2050, the modeled transportation electrification results in a load increase of $13 \%$ relative to the non-electrification case.
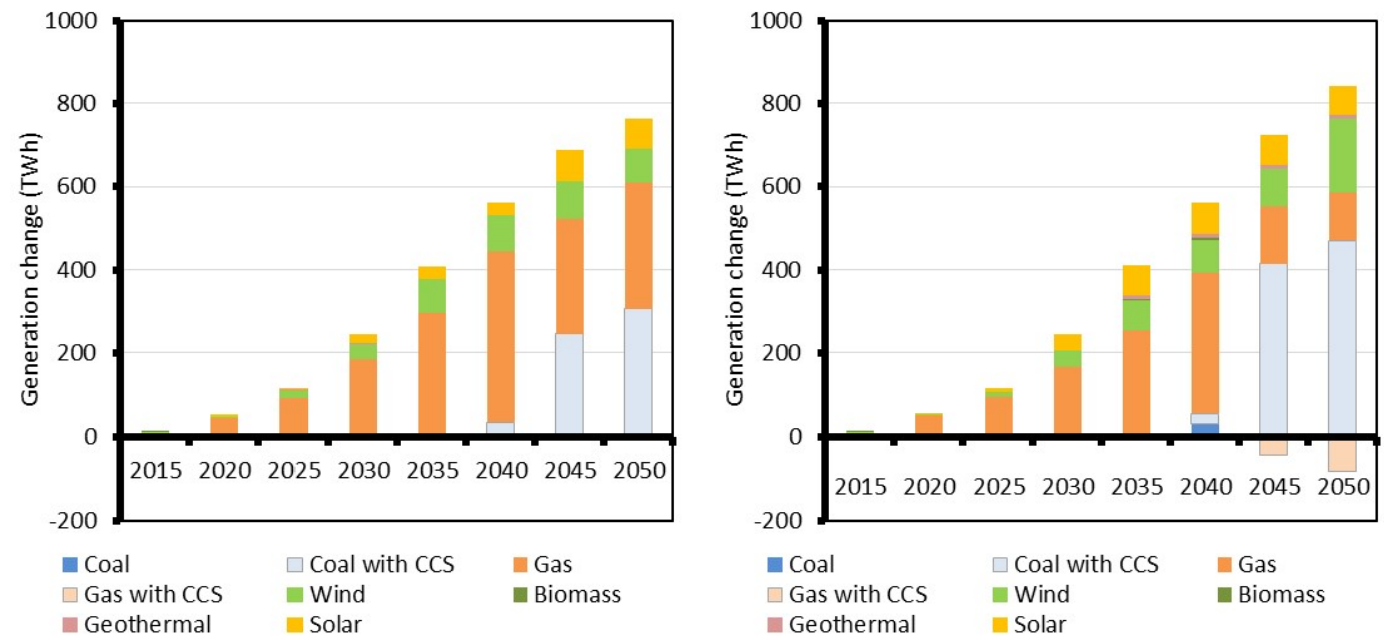

Figure 5: Incremental generation due to transportation electrification in the Base GHG Scenario (left) and Lower GHG Scenario (right)

\subsection{Grid Greenhouse Gas Emissions}

Figure 6 shows the greenhouse gas emissions attributable to electricity generation in both scenarios for the non-electrification case (solid) and the marginal generation due to transportation electrification (dotted). All results include upstream emissions attributable to electricity fuels and transmission and distribution losses. In the non-electrification case the grid emissions rates generally decline as current levels of fossil generation, particularly coal generation, are replaced by additional shares of renewable generation. Marginal grid emissions are generally lower than or comparable to average emissions, although in the post-2040 timeframe average emissions rates decrease below the level of marginal emissions rates. 


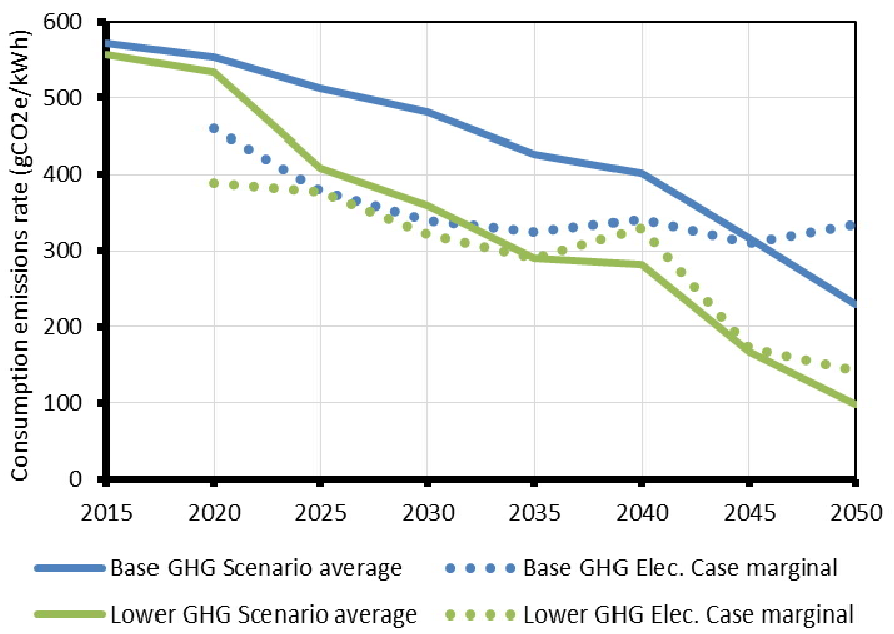

Figure 6: Average and marginal grid emissions in the Base GHG Scenario and Lower GHG Scenario

\section{Transportation Emissions}

The grid emissions described above in Section 4 were combined with the vehicle characteristics described in Section 3 to calculate total vehicle emissions. In order to provide a complete comparison of greenhouse gas emissions, upstream emissions were added to both petroleum and electricity direct emissions and battery manufacturing emissions were added, all based on the 2014 version of the Greenhouse Gases, Regulated Emissions, and Energy Use in Transportation (GREET) model. Figure 7 shows a per-vehicle comparison between conventional vehicles and PEVs for 2015 and for 2050. The emissions of a PEV are significantly lower in both time periods, and the Lower GHG Scenario reduces grid emissions relative to the Base GHG Scenario.

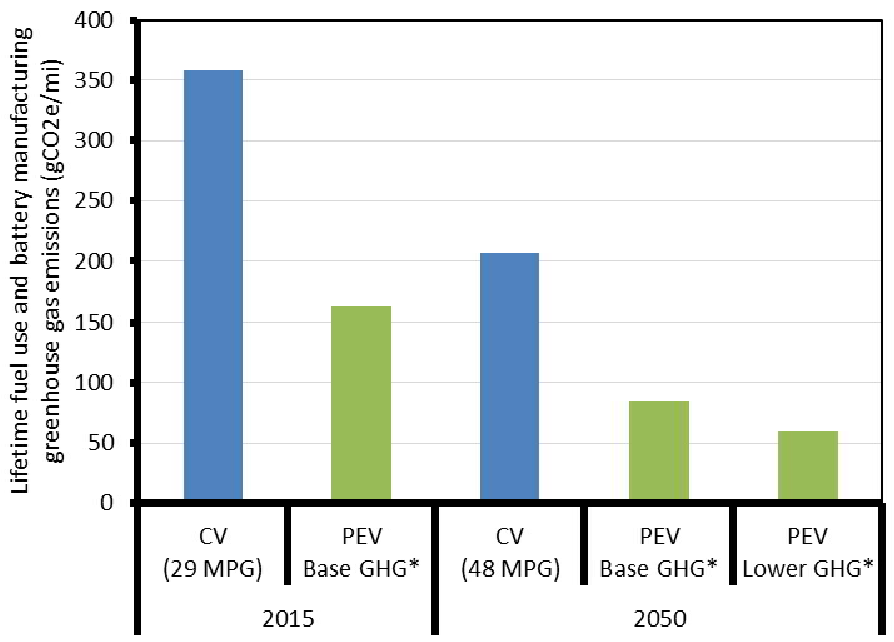

Figure 7: Comparison between conventional vehicles and PEVs

* PEV emissions include battery-manufacturing emissions and full-fuel-cycle emissions for electricity and gasoline, averaged over a 150,000 mile vehicle lifetime. Utility factor for the PEV is $87 \%$.

\subsection{Changes in Transportation Emissions}

The increased introduction of PEVs shown in Figure 1 and the reduction in per-vehicle emissions shown in Figure 7 result in reductions in overall transportation emissions, as shown in Figure 8 for passenger vehicles. In Figure 8, the blue patches show emissions for conventional passenger vehicles and the green patches show grid emissions attributable to passenger PEVs. The black dotted line shows what emissions would be if electrification were not possible and the PEVs were replaced with conventional vehicles; note that emissions 
still decrease in this case due to increasing conventional vehicle fuel efficiency (despite increases in miles driven), but they do not decrease as much as they can with transportation electrification. Although not shown, electricity emissions decrease in the Lower GHG Scenario.

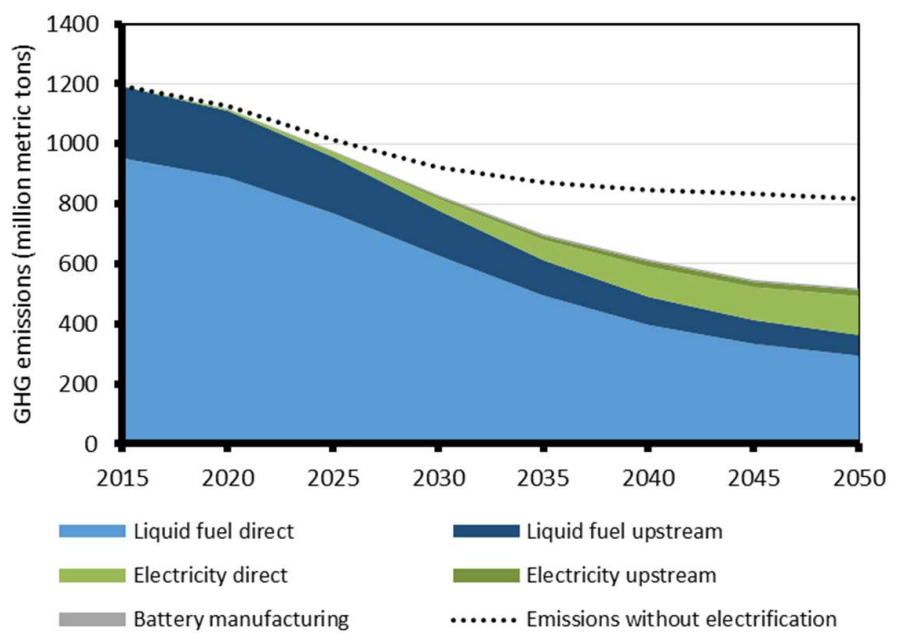

Figure 8: Emissions for passenger vehicles in the Base GHG Scenario

Commercial vehicles and non-road equipment represent a smaller but still significant fraction of transportation emissions. Figure 9 shows total modeled transportation-sector emissions for the Base GHG Scenario. In the Lower GHG Scenario electrification emissions (the grey patch) decrease so total emissions are lower.

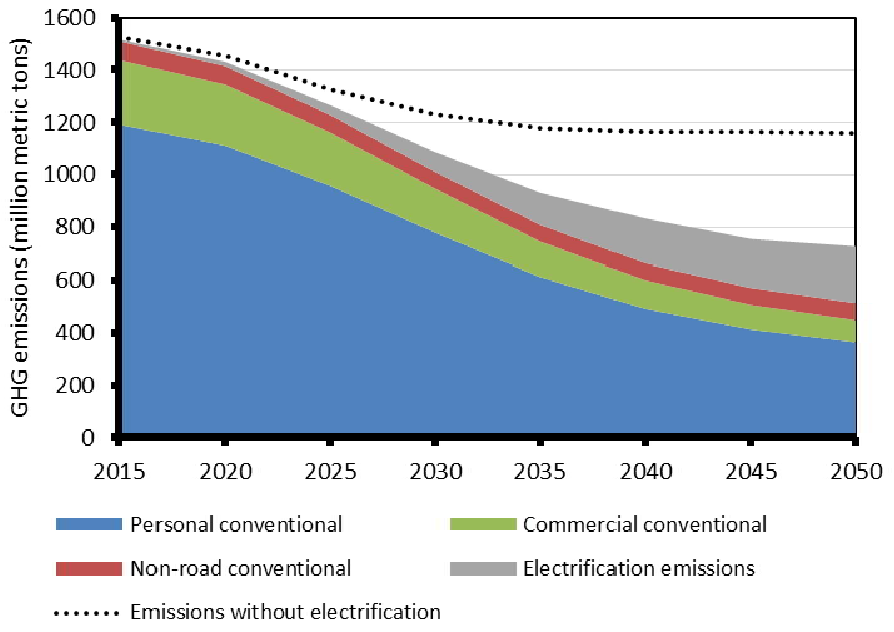

Figure 9: Transportation sector emissions over time in the Base GHG Scenario

\section{Multisector Greenhouse Gas Emissions}

Figure 10 shows the combined emissions for the electricity and transportation sectors, including the portion of on-road transportation emissions which were not considered to be electrifiable (most of this is attributable to long-distance trucking). In both cases, emissions decrease between 2015 and 2050 (note that emissions for both sectors include upstream emissions, which could also be considered to be 'Industrial' sector emissions; in this analysis they are attributed to the end-use transportation sector). The Lower GHG Scenario assumptions reduce 2050 grid emissions by almost $60 \%$, but overall 2050 emissions for the two sectors only reduce by $25 \%$, since transportation sector emissions are relatively constant. 

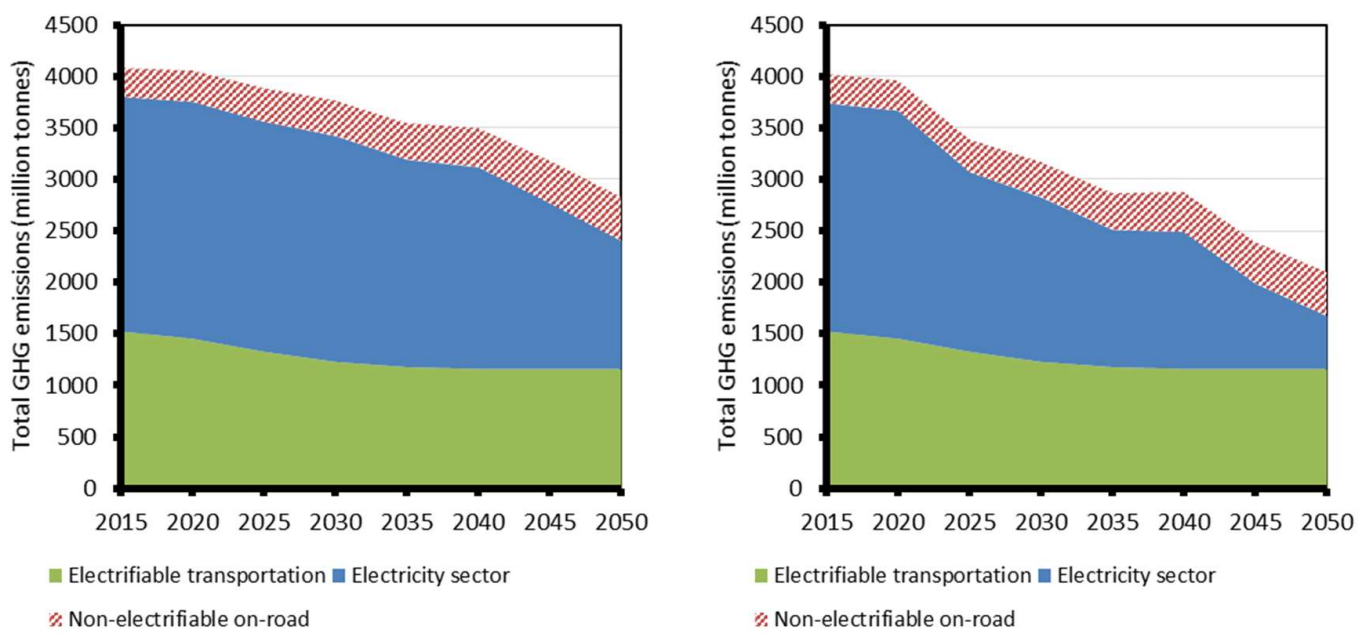

Figure 10: Transportation sector and electricity sector GHG emissions without transportation electrification in the Base GHG Scenario (left) and Lower GHG Scenario (right)

Figure 11 shows the combined emissions for the electricity and transportation sectors with transportation electrification. In the Base GHG Scenario, transportation electrification leads to a 35\% reduction in 2050 GHG emissions for the electrifiable transportation sector, reducing total 2050 emissions by $15 \%$ relative to the 2050 Base GHG Scenario results without electrification. The Lower GHG Scenario leverages the cleaner grid to further reduce transportation sector emissions, so total 2050 emissions are $45 \%$ lower than the Base GHG Scenario without electrification. This case also results in a $60 \%$ reduction from 2015 emissions for the two sectors.
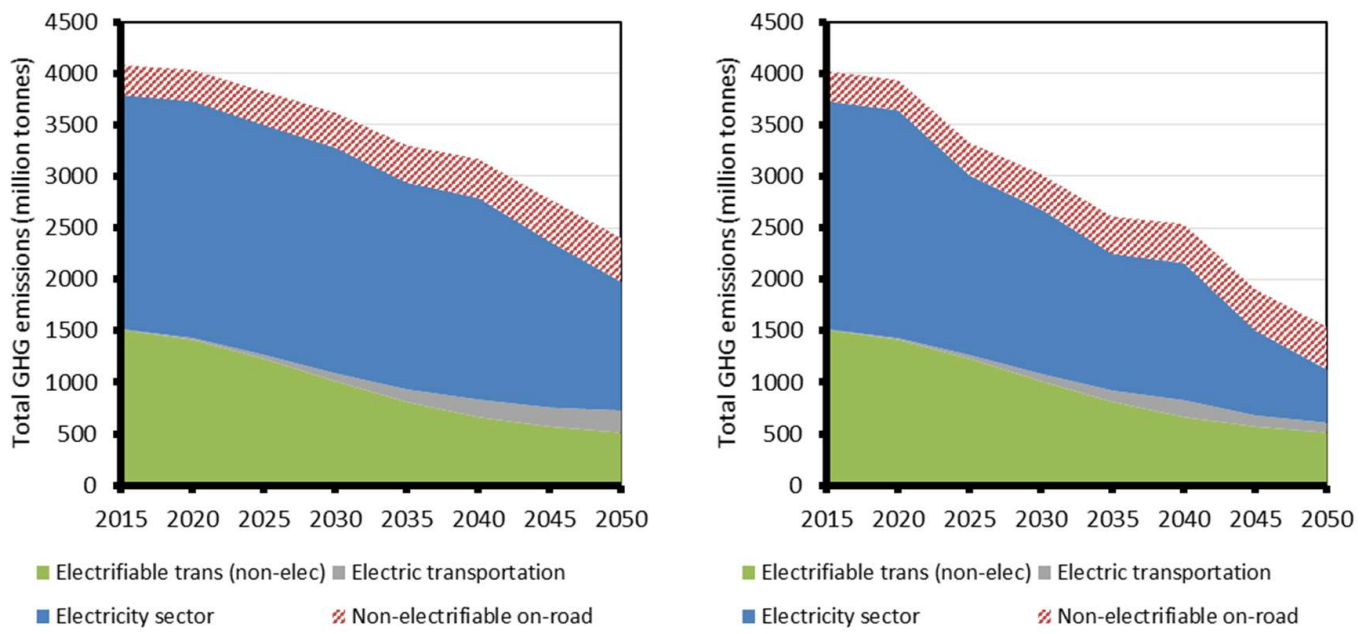

Figure 11: Multisector GHG emissions with transportation electrification in the Base GHG Scenario (left) and Lower GHG Scenario (right)

\section{Discussion}

\section{References}

[1] EPRI-NRDC. Environmental Assessment of a Full Electric Transportation Portfolio: Volume 1: Background, Methodology, and Best Practices. Palo Alto, CA: 2015. 3002006875.

[2] EPRI-NRDC. Environmental Assessment of a Full Electric Transportation Portfolio: Volume 2: Greenhouse Gas Emissions. Palo Alto, CA: 2015. 3002006876. 
[3] National Research Council (U.S.). Committee on Transitions to Alternative Vehicles and Fuels. Transitions to Alternative Vehicles and Fuels. Washington, D.C.: National Academies Press. 2013.

[4] EPRI-NRDC. Environmental Assessment of On-road Vehicle and Off-road Equipment Electrification: Volume 3: Air Quality Impacts. EPRI, Palo Alto, CA: 2015. 3002006880.

\section{Authors}

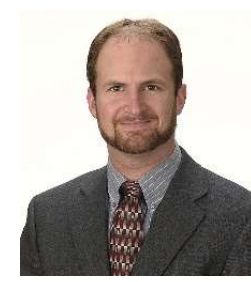

Marcus Alexander: Mr. Alexander has a B.S in Mechanical Engineering and a M.S. in Electrical Engineering, both from the University of California, Davis, is currently Manager, Vehicle Systems Analysis at the Electric Power Research Institute. He has worked the PEV industry for almost 20 years in a variety of roles, from helping design and build them, to modeling them, to modeling their effects on the utility grid.

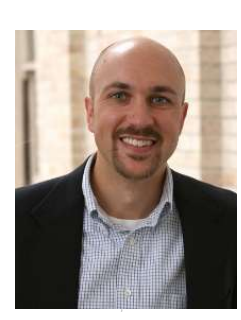

Luke Tonachel: Mr. Tonachel holds a B.S. in Mechanical Engineering from the University of Rochester and Masters in Public Policy from University of California, Berkeley. He is the Director of the Clean Vehicles and Fuels team and a senior analyst for the Natural Resources Defense Council (NRDC), an international nonprofit environmental advocacy organization. Since joining NRDC in 2004, his focus has been on reducing the environmental impacts of the world's transportation demands by advocating for policies that develop and commercialize cleaner, more efficient vehicles and non-petroleum fuels. Mr. Tonachel has authored and contributed to numerous nationally-recognized reports and analyses covering vehicle electrification, improved vehicle efficiency and other oil and emissions reduction opportunities. 